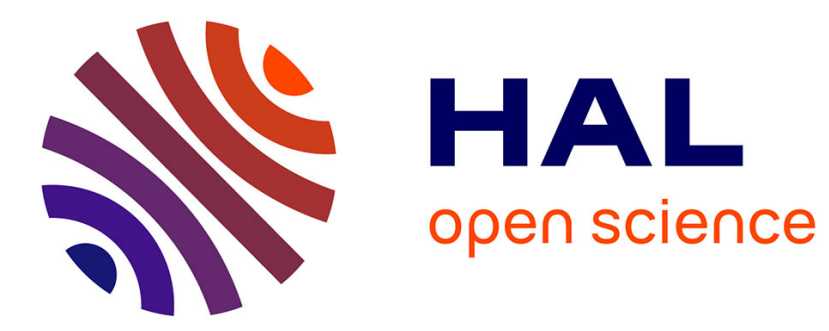

\title{
On rotational instability within the nonlinear six-parameter shell theory
}

Jacek Chróścielewski, Francesco Dell'Isola, Victor A. Eremeyev, Agnieszka Sabik

\section{> To cite this version:}

Jacek Chróścielewski, Francesco Dell'Isola, Victor A. Eremeyev, Agnieszka Sabik. On rotational instability within the nonlinear six-parameter shell theory. International Journal of Solids and Structures, 2020, 196-197, pp.179-189. 10.1016/j.ijsolstr.2020.04.030 . hal-02917570

\section{HAL Id: hal-02917570 \\ https://hal.science/hal-02917570}

Submitted on 19 Aug 2020

HAL is a multi-disciplinary open access archive for the deposit and dissemination of scientific research documents, whether they are published or not. The documents may come from teaching and research institutions in France or abroad, or from public or private research centers.
L'archive ouverte pluridisciplinaire HAL, est destinée au dépôt et à la diffusion de documents scientifiques de niveau recherche, publiés ou non, émanant des établissements d'enseignement et de recherche français ou étrangers, des laboratoires publics ou privés. 


\title{
On rotational instability within the nonlinear six-parameter shell theory
}

\author{
Jacek Chróścielewski ${ }^{\mathrm{a}}$, Francesco dell'Isola ${ }^{\mathrm{b}, \mathrm{c}}$, Victor A. Eremeyev ${ }^{\mathrm{a}, \mathrm{c}}$, Agnieszka Sabik ${ }^{\mathrm{a}, *}$ \\ ${ }^{a}$ Gdańsk University of Technology, Faculty of Civil and Environmental Engineering, ul. Gabriela Narutowicza 11/12, 80-233 Gdańsk, Poland \\ ${ }^{\mathrm{b}}$ International Research Center on Mathematics and Mechanics of Complex System (MEMOCS), Università degli Studi dell'Aquila, Via Giovanni Gronchi 18, \\ Zona industriale di Pile L'Aquila 67100, Italy \\ ${ }^{\mathrm{c}}$ Research Institute for Mechanics, National Research Lobachevsky State University of Nizhni Novgorod, Russia
}

\begin{abstract}
A B S T R A C T
Within the six-parameter nonlinear shell theory we analyzed the in-plane rotational instability which occurs under in-plane tensile loading. For plane deformations the considered shell model coincides up to notations with the geometrically nonlinear Cosserat continuum under plane stress conditions. So we considered here both large translations and rotations. The constitutive relations contain some additional micropolar parameters with so-called coupling factor that relates Cosserat shear modulus with the Cauchy shear modulus. The discussed instability relates to the bifurcation from the static solution without rotations to solution with non-zero rotations. So we call it rotational instability. We present an elementary discrete model which captures the rotational instability phenomenon and the results of numerical analysis within the shell model. The dependence of the bifurcation condition on the micropolar material parameters is discussed.
\end{abstract}

\section{Introduction}

Theory of elastic stability has an origin in the famous elastica problem considered by Leonhard Euler $(1744,1757,1778)$. After Euler the analysis of elastic stability was mostly performed in the case of thin structures, that is for rods, beams, trusses, frames, plates and shells, see, e.g., Timoshenko and Gere (1989); Panovko and Gubanova (1972); Vol'mir (1970); Antman (2005). Euler's technique for 3D solids was developed in much lesser number of publications, see, e.g., Green and Adkins (1960); Lurie (1990); Ogden (1997); Fu and Ogden (1999); Eremeev and Zubov (2017) and the references therein. Let us note that instability typically occurs under compressive loading for thin structures and for 3D solids. Nevertheless, in the literature results on instability under tensile loads are also known, see, e.g., Panovko and Gubanova (1972); Zubov and Rudev (1996); Zubov and Lastenko (2004); Zubov and Sheidakov (2005); Eremeyev et al. (2007). In particular, considering tension of an elastic prism within the nonlinear theory of elasticity, in Zubov and Rudev (1996) it was proven that the bifurcation points, if exist, lie on the declined

\footnotetext{
* Corresponding author.

E-mail addresses: jacek.chroscielewski@pg.edu.pl (J. Chróścielewski), francesco.dellisola.aquila@gmail.com (F. dell'Isola), eremeyev.victor@gmail.com (V.A. Eremeyev), agsa@pg.edu.pl (A. Sabik).
}

branch of a loading curve. The same behavior was observed for the bifurcation of an elastic sphere under inner pressure by Eremeyev et al. (2007). In order to demonstrate the instability under tension the simple elastic beam-like structures with sliders were invented by Zaccaria et al. (2011); Bigoni et al. (2018).

The results on elastic stability analysis were extended for generalized media. Let us note that the interest to such enhanced models of continuum grows with respect to modelling of new micro- and nano-structured materials, such as metamaterials, beam-lattices, granular materials, masonries, soils, composites, etc. Among the generalized models of continuum such as strain- and stress-gradient elasticity and plasticity, micromorphic media, it is worth to mention the Cosserat continuum model called also micropolar medium (Nowacki, 1986; Eringen, 1999; Eremeyev et al., 2013). Within this model the kinematics is described through two kinematically independent fields of translations and rotations. This approach found various applications in modelling of media with essential rotational interactions, such as porous media (Lakes, 1986; Rueger and Lakes, 2016; 2019), bones (Park and Lakes, 1986; Goda et al., 2012; 2014), beam-lattices (Suiker et al., 2001; El Nady et al., 2017; Eremeyev, 2019), granular media (Walsh and Tordesillas, 2004; Vardoulakis, 2019), and masonries (Masiani and Trovalusci, 1996; Besdo, 2010; Trovalusci and Pau, 2014; Leonetti et al., 2018), composites and inhomogeneous mate- 


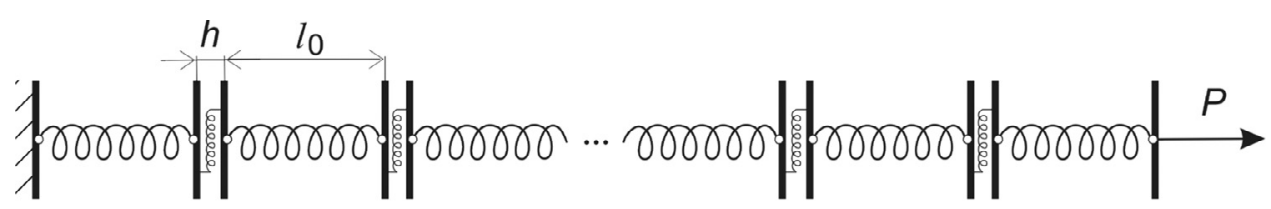

a)

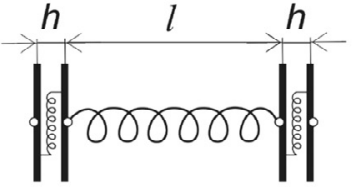

b)

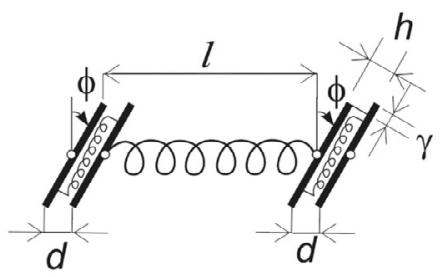

c)

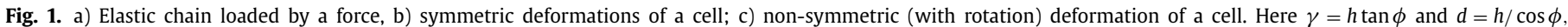
where $h$ is a constant distance between sliders, $l_{0}$ and $l$ are lengths of springs before and after deformation.

rials (Bigoni and Drugan, 2007; Reccia et al., 2018; Hütter, 2019), see also Eremeyev et al. (2013) and the reference therein.

Let us note that the main sources for Cosserat constitutive equations are not only the straightforward experiments on microstructured materials as reported by Lakes (1986); Rueger and Lakes (2016, 2019); Park and Lakes (1986) but also some homogenization techniques applied to microstructured materials such as beam-lattices. Depending on the assumed material microstructure the homogenization may lead even to more general constitutive relations as the strain gradient elasticity (AbdoulAnziz and Seppecher, 2018; Abdoul-Anziz et al., 2019) or micromorphic media (Misra and Poorsolhjouy, 2016; 2017; Biswas and Poh, 2017). For example, such particular class of metamaterials called pantographic lattices could be described using a modified strain gradient elasticity, see Rahali et al. (2015); dell'Isola et al. (2016); Placidi et al. (2016); Turco et al. (2016, 2018); Barchiesi et al. (2019); De Angelo et al. (2019); dell'Isola et al. (2019a,b).

The Cosserat approach can be adopted to rods, plates and shells, see, e.g., Rubin (2000); Antman (2005); Eremeyev et al. (2013). Let note that the considered in this paper nonlinear resultant six-parametric shell theory presented in (Libai and Simmonds, 1998; Chróścielewski et al., 2004) coincides kinematically with the 2D Cosserat continuum, therefore it is also called the micropolar shell theory, see, e.g., Eremeyev et al. (2013); Eremeyev and Altenbach (2017). In particular for in-plane deformations, a micropolar plate almost corresponds to a 2D Cosserat continuum. Obviously, the enhanced kinematics requires efficient numerical tool. For example, even in one-dimensional case it is still of interest, see, e.g., FEM implementations for beams Greco and Cuomo (2013, 2014); Eugster et al. (2014); Cazzani et al. (2016a,b); Niiranen et al. (2019) and the references therein. The FEM implementation of six-parameter theory was developed by Chróścielewski et al. (1992, 1997, 2004); Chróścielewski and Witkowski (2006); Chróścielewski et al. (2016); Burzyński et al. (2016, 2018); Chróścielewski et al. (2019), where its efficiency was demonstrated for various static and dynamic problems.

For the Cosserat media, the elastic instability is more complex, in general, and much less investigated, see Eremeyev and Zubov (1994); Sheydakov and Altenbach (2016); Lakes (2018), where it was shown that the micropolar properties of a material may significantly affect values of critical loads and buckling modes. In a certain sense this behavior of continuum models could be confirmed through the analysis of beam-lattice materials as such materials have a relation to micropolar media, see Scerrato et al. (2016); Giorgio et al. (2018); Eremeyev and Turco (2020).
The aim of this paper is to discuss the new type of elastic instability under tension which we call the rotational instability. The paper is organized as follows. In Section 2 we introduce the discrete system with translational and rotational degrees of freedom which demonstrate the rotational instability phenomenon related to a switching between solutions with zero and non-zero rotations. Section 3 addresses the governing equations of the shell model and its FEM implementation based on the incremental formulation of the virtual work principle. Finally, Section 4 contains the results of numerical analysis which show similarities in rotational instability with the discrete model. Here we consider three different micropolar materials.

\section{Rotational instability of an elastic chain with translational and rotational degrees of freedom}

In order to illustrate the discussed phenomenon of the rotational instability, we consider first a chain with elements possessing both translational and rotational degrees of freedom. Let the chain be consisted of $n$ elastic cells as shown in Fig. 1. Each cell constitutes from two rigid bars connected by an elastic spring of stiffness $K_{t}$ and initial length $\ell_{0}$. Cells interact to each other through a shear spring of stiffness $K_{s}$. So the neighbouring bars may slide between each other. The distance between neighbouring bars is assumed to be constant $h$. We also assume that bars can rotate and $\phi$ is an angle of rotation. This chain structure is similar to the rigid elements developed by Casolo (2004, 2006); Casolo and Pena (2007); Bertolesi et al. (2018) applied to model masonry structures, but here we restrict ourselves by $1 \mathrm{D}$ case. The chain is loaded by tensile force $P$ on the right end whereas the left end of the chain is clamped.

Considering homogeneous deformations only, that is assuming the same strain $\varepsilon$ and rotation $\phi$ for each cell, the total energy of the chain becomes

$\mathcal{E}=\mathcal{E}(\varepsilon, \phi)=\frac{1}{2} K_{t} n \varepsilon^{2}+\frac{1}{2} K_{s}(n-1) \gamma^{2}-P n u$,

where

$\varepsilon=\frac{\ell-\ell_{0}}{\ell_{0}}, \quad \gamma=h \tan \phi, \quad u=\ell_{0} \varepsilon+\frac{h}{\cos \phi}-h$,

and $\ell$ is a length of a spring after deformation. Here $\varepsilon$ is a stretching strain, $\gamma$ is a shear, and $u$ is a displacement of the chain right end.

The equilibrium conditions follow from the stationarity of $\mathcal{E}$ that is from the relations

$\frac{\partial \mathcal{E}}{\partial \varepsilon}=0, \quad \frac{\partial \mathcal{E}}{\partial \phi}=0$. 


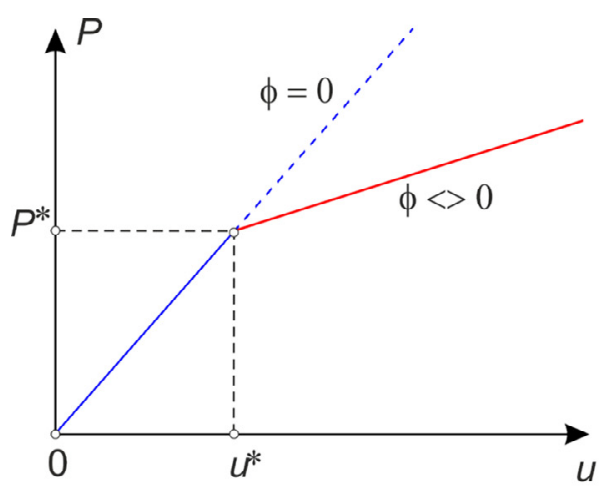

a)

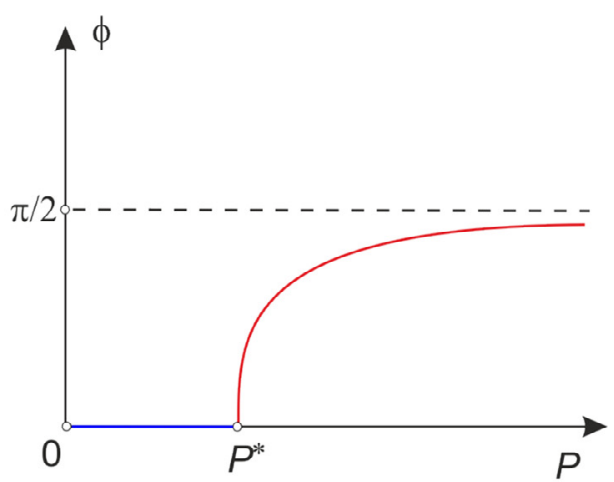

b)

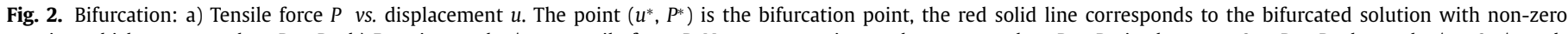

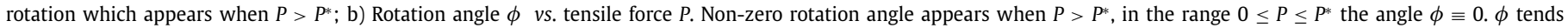
to $\pi / 2$ at $P \rightarrow \infty$. (For interpretation of the references to color in this figure legend, the reader is referred to the web version of this article.)

With (1) these equations take the form

$K_{t} \varepsilon-P \ell_{0}=0$,

$\tan \phi\left(\frac{K_{s} h(n-1)-P n \cos \phi}{\cos ^{2} \phi^{2}}\right)=0$.

Eq. (2) gives one solution for $\varepsilon$ while Eq. (3) has trivial solution $\phi=0$ and nontrivial one given by

$\phi=\arccos \left(\frac{K_{s} h(n-1)}{P n}\right)$,

which is valid when

$P \geq P^{*} \equiv \frac{K_{s} h(n-1)}{n}$.

Trivial solution describes the symmetric extension of the chain as a elastic linear spring whereas the non-trivial solution corresponds to the non-symmetric rotational mode which occurs when $P$ exceeds a critical force. The typical loading curves are shown in Fig. 2a and the dependence $P-\phi$ is given in Fig. 2b. Here we consider the case when the stiffness of the shear springs is lesser than the stiffness of tensile springs. This graph has the form of typical buckling behavior for an elastic rod, see, e.g., Panovko and Gubanova (1972); Antman (2005). During the loading first we have the linear symmetric solution with $\phi=0$, then at the bifurcation point $\left(u^{*}=P^{*} / K_{t}, P^{*}\right)$ new branch appears which relates to softening and rotations of the bars in the chain. In Fig. 2a the blue line starting at the point $(0,0)$ corresponds to the shape of the chain given in Fig. 1b. The rotational mode as shown in Fig. 1c is described by the red line which starts at point $\left(u^{*}, P^{*}\right)$.

The considered chain model demonstrates similar behavior of elastic systems with sliding interfaces under tensile forces discussed in Zaccaria et al. (2011); Bigoni et al. (2018); Eremeyev and Turco (2020).

\section{Basic equations of the six-parameter shell theory and FEM formulation}

Following Libai and Simmonds (1998); Chróścielewski et al. (2004) let us briefly introduce the basic equations of the sixparameter shell theory. The kinematics of the shells is described through the translation field $\mathbf{u}=\mathbf{y}-\mathbf{x}$, where $\mathbf{y}$ and $\mathbf{x}$ are position vectors of the shell base surface in current and reference placements, respectively, and through the orthogonal tensor $\mathbf{Q}$ which describes rotations of cross-section of the shell. The Lagrangian equilibrium equations take the form

$\operatorname{Div}_{S} \mathbf{N}+\rho \mathbf{f}=\mathbf{0}$,

$\operatorname{Div}_{S} \mathbf{M}+\operatorname{ax}\left(\mathbf{N F}^{T}-\mathbf{F N}^{T}\right)+\rho \mathbf{c}=\mathbf{0}$,

where $\mathbf{N}$ and $\mathbf{M}$ are the surface stress resultant tensor and the surface couple stress tensor both of Piola type, $\mathbf{F}=\operatorname{Grad}_{S} \mathbf{y}$ is the surface deformation gradient, $\rho>0$ is the referential resultant surface mass density, $\mathbf{f}$ and $\mathbf{c}$ are the resultant surface force and couple vectors per unit mass, respectively. In addition, Div ${ }_{S}$ and $\operatorname{Grad}_{S}$ are the surface divergence and gradient operators defined as in (Gurtin and Murdoch, 1975) and ax(A) denotes the axial vector associated with a skew tensor $\mathbf{A}$.

For a hyperelastic shell there is a strain energy density $W$ which depends on two 2D strain measures

$W=W(\mathbf{E}, \mathbf{K}), \quad \mathbf{E}=\mathbf{Q}^{T} \mathbf{F}-\mathbf{I}, \quad \mathbf{K}=\mathbf{Q}^{T} \mathbf{C F}-\mathbf{B}$,

such that

$\mathbf{N}=\mathbf{Q}^{T} \tilde{\mathbf{N}}, \quad \mathbf{M}=\mathbf{Q}^{T} \tilde{\mathbf{M}}, \quad \tilde{\mathbf{N}}=\frac{\partial W}{\partial \mathbf{E}}, \quad \tilde{\mathbf{M}}=\frac{\partial W}{\partial \mathbf{K}}$.

Here tensors $\tilde{\mathbf{N}}$ and $\tilde{\mathbf{M}}$ are the surface 2D stress measures of 2nd Piola-Kirchhoff type of the shell, $\mathbf{C}$ and $\mathbf{B}$ are the structure tensors of the shell in the reference and actual placements (Chróścielewski et al., 2004; Eremeyev and Pietraszkiewicz, 2006), respectively, and I is the $3 \mathrm{D}$ unit tensor. In what follows we consider a physically linear shell that is when $W$ is a quadratic function of $\mathbf{E}$ and $\mathbf{K}$. So $\tilde{\mathbf{N}}$ and $\tilde{\mathbf{M}}$ become linear functions of $\mathbf{E}$ and $\mathbf{K}$, see Eremeyev and Pietraszkiewicz (2006, 2012); Eremeyev et al. (2013) for more detail. Various variational principles for statics and dynamics of sixparameter shells were formulated by Chróścielewski et al. (2004); Eremeyev et al. (2013).

\subsection{Plane stress state}

In this study we consider a plane stress state. In this case we have significant reduction in a number of components of stress and strain measures. In particular, translations and rotations can be written in the form

$\mathbf{u}=u_{1} \mathbf{i}_{1}+u_{2} \mathbf{i}_{2}, \quad \mathbf{Q}=\mathbf{Q}\left(\phi \mathbf{i}_{3}\right)$,

where $\mathbf{i}_{k}, k=1,2,3$, are the Cartesian base vectors related to the Cartesian Lagrangian coordinates $x, y, z$, and $\mathbf{Q}\left(\phi \mathbf{i}_{3}\right)$ denotes the 
rotation tensor about $\mathbf{i}_{3}$ through an angle $\phi$. We collect non-zero components of the strain measures into the vector

$\mathbb{E}(\mathbb{U})=\left(\begin{array}{c}E_{11} \\ E_{22} \\ E_{12} \\ E_{21} \\ K_{13} \\ K_{23}\end{array}\right)=\left(\begin{array}{c}u_{1,1}+1-\cos \phi \\ u_{2,2}+1-\cos \phi \\ u_{1,2}+\sin \phi \\ u_{2,1}-\sin \phi \\ \phi_{, 1} \\ \phi_{, 2}\end{array}\right)$,

where $\mathbb{U}=\left(u_{1}, u_{2}, \phi\right)^{T}$. Here for brevity we denote partial derivatives through lower indices after comma, $(\ldots)_{1}=\partial(\ldots) / \partial x$ and $(\ldots)_{, 2}=\partial(\ldots) / \partial y$.

In a similar way we introduce the vector of stress and couples measures as follows

$\mathbb{S}=\left(N_{11}, N_{22}, N_{12}, N_{21}, M_{13}, M_{23}\right)^{T}$.

\subsection{Constitutive relations}

Preliminary numerical studies shown that the higher the shear flexibility of the material, the lower the range of deformations is associated with rotational instability. For example, such materials are fiber reinforced composites. Therefore in what follows we consider the physically linear orthotropic material. For plane stress state this relation takes the form given by Chróścielewski et al. (2019)

$\mathbb{S}=\mathbb{C E}$

where

$$
\mathbb{C}=\left(\begin{array}{cccccc}
\frac{E_{1}}{1-v_{12} \nu_{21}} & \frac{v_{12} E_{2}}{1-v_{12} \nu_{21}} & 0 & 0 & 0 & 0 \\
\frac{\nu_{21} E_{1}}{1-v_{12} \nu_{21}} & \frac{E_{2}}{1-v_{12} \nu_{21}} & 0 & 0 & 0 & 0 \\
0 & 0 & G_{12}+G_{c} & G_{12}-G_{c} & 0 & 0 \\
0 & 0 & G_{12}-G_{c} & G_{12}+G_{c} & 0 & 0 \\
0 & 0 & 0 & 0 & 2 G_{12} \ell_{c}^{2} & 0 \\
0 & 0 & 0 & 0 & 0 & 2 G_{12} \ell_{c}^{2}
\end{array}\right) \text {, }
$$

and $E_{1}$ and $E_{2}$ are Young's moduli in two orthogonal directions in a plane, $G_{12}$ is the shear modulus in the same plane, and $v_{12}$ and $v_{21}$ denote Poisson's ratios such that $E_{1} v_{21}=E_{2} v_{12}$. In addition, we have two micropolar elastic parameters that are the characteristic length $\ell_{c}$ and the Cosserat coupling number $N$ which relates $G_{12}$ and $G_{c}$ through the relation (Nakamura et al., 1984; Lakes, 1986)

$G_{c}=\frac{N^{2}}{1-N^{2}} G_{12}$,

and $0 \leq N^{2}<1$. Next, having $E_{1}, E_{2}, G_{12}, v_{12}, v_{21}$, and $\ell_{c}$ fixed, we consider the dependence of the stability loss on $N$. In particular, the value $N=0$ corresponds to the decoupled system of equations in which the stress tensor coincides with one for a Cauchy material.

For the general framework related to the anisotropic constitutive relations of micropolar materials we refer to Eremeyev and Pietraszkiewicz (2006); Chróścielewski et al. (2019) for shells and to Nakamura et al. (1984); Eringen (1999); Eremeyev and Pietraszkiewicz (2012, 2016); Casolo (2006) for 3D solids.

\subsection{Numeric procedure}

The numerical analysis is based on the virtual work principle and the finite element technique formulated in the form given by Chróścielewski and Witkowski (2006)

$\mathcal{G}[\mathbb{U} ; \mathbb{W}] \equiv \mathcal{G}_{i}[\mathbb{U} ; \mathbb{W}]-\mathcal{G}_{e}[\mathbb{U} ; \mathbb{W}]=0$, where

$$
\begin{aligned}
& \mathcal{G}_{i}[\mathbb{U} ; \mathbb{W}]=\iint_{B} \mathbb{E}^{T}(\mathbb{W}) \mathbb{S}[\mathbb{E}(\mathbb{U})] \mathrm{d} a, \\
& \mathcal{G}_{e}[\mathbb{U} ; \mathbb{W}]=\iint_{B} \mathbb{W}^{T} \mathbb{P} \mathrm{d} a+\int_{\partial B_{f}} \mathbb{W}^{T} \mathbb{F} \mathrm{d} s
\end{aligned}
$$

are the virtual work of internal stress resultants and couplestresses, and external forces and couples, respectively, $\mathbb{W}=$ $\left(v_{1}, v_{2}, \omega\right)$ with virtual translations $v_{1}, v_{2}$, and virtual rotation $\omega$. Here $B$ is a reference base surface of the shell, whereas $\partial B_{f}$ is a part of its boundary, where external forces and couples are applied, $\mathbb{P}$ and $\mathbb{F}$ describe surface and contour loadings, respectively. The incremental realization of (13) with Newton's method is applied, which can be represented as follows

$\mathcal{G}[\mathbb{U} ; \Delta \mathbb{U} ; \mathbb{W}]+\mathcal{G}[\mathbb{U} ; \mathbb{W}]=0$,

where $\Delta \mathbb{U}$ denotes an increment of displacement vector. For more detail of the FEM implementation of nonlinear six-parameter shells we refer to Chróścielewski et al. (2004); Chróścielewski and Witkowski (2006); Chróścielewski et al. (2016); Burzyński et al. (2016, 2018); Chróścielewski et al. (2019).

\section{Numerical results}

In this section few numerical examples are presented which show the rotational instability phenomenon arising in axially loaded two-dimensional samples. In the computations the Authors' own FEM code is used basing on the six-parameter shell theory with asymmetric strain and stress measures, as described in the previous section. In the discretization the fully integrated 16-node shell element (16 FI) is employed. In all discussed examples the characteristic length is assumed to be a small value $\ell_{c}=0.02 \mathrm{~mm}$.

As mentioned previously, in this work only the influence of the Cosserat coupling number $N$ on the material stability is studied. The impact of the characteristic length is at this stage neglected.

\subsection{Example 1}

Let us start with the consideration of an ideal strip subjected to an uniaxial tension. The term ideal is related to the following features of the problem:

- the strip is made of the isotropic material,

- the strip is free to shrink in the direction perpendicular to the load direction.

As an isotropic material the steel is chosen with $E_{1}=E_{2}=200$ GPa and $v_{12}=v_{21}=0.3$. The release of the transverse deformation provides a homogeneous stress distribution in the strip. Hence, there is no shear strain and rotation field present in the structure. To induce the rotational field a small imperfection is introduced in the form of a small drilling moment placed in the center of the structure (Fig. 3).

Two samples with different geometrical data are analyzed, namely: $L=150 \mathrm{~mm}, B=25 \mathrm{~mm}, t=2 \mathrm{~mm}$ and $L=100 \mathrm{~mm}$, $B=50 \mathrm{~mm}, t=0.5 \mathrm{~mm}$. For both geometries two meshes $n \times m$ were adopted, where $n$ stands for number of elements along the axial direction and $m$ is the number of elements along the width of the sample. Fig. 4 depicts the stress-strain relation for both strips and meshes obtained for $N=0.01$. As the stress measure the ratio force per area of the sample is chosen $(P / A)$, while the relative elongation $(u / L)$ is understood as the strain size. It is observed that, regardless the considered geometry data and mesh density, at certain point corresponding to $P / A=31 \mathrm{MPa}$ the characteristic change of the path arises. This value of the stress will be named critical stress $\sigma_{\text {crit }}$. 


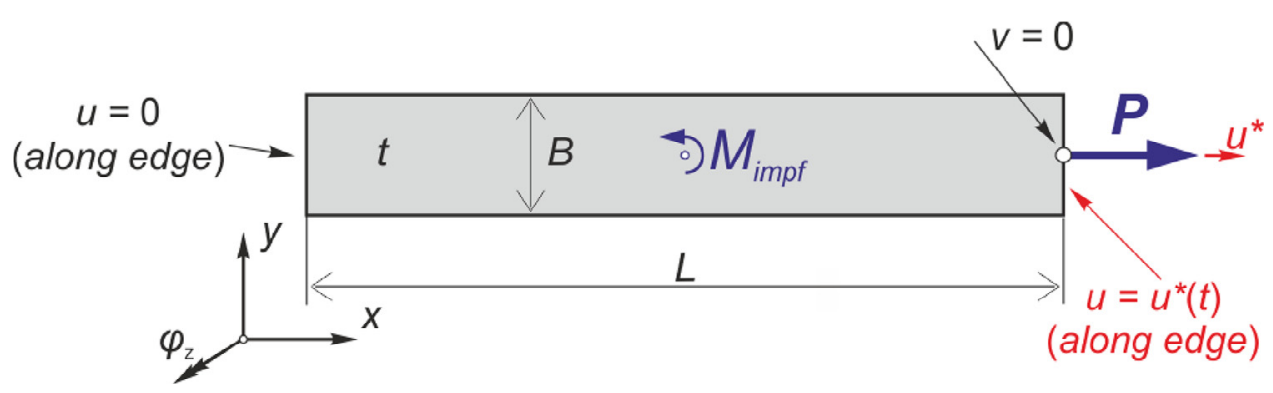

Fig. 3. Ideal strip - geometry and boundary conditions. The strip is loaded through a force $P$ and a small moment $M_{i m p}$.

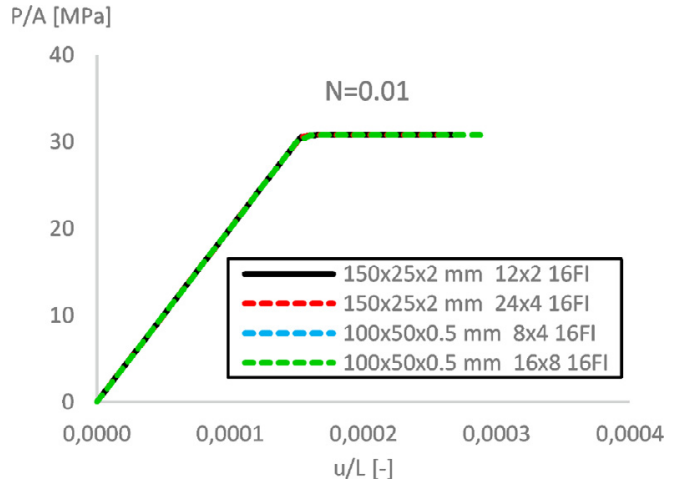

Fig. 4. Stress-strain relation for ideal steel strips $150 \times 25 \times 2 \mathrm{~mm}$ and $100 \times 50 \times 0.5 \mathrm{~mm}, N=0.01$, two discretizations.

For the same value of $N=0.01$ in Fig. 5 the influence of the imperfection value is illustrated. Figs. $5 \mathrm{a}$ and $5 \mathrm{~b}$ show the stressstrain and stress-center rotation curve, respectively. It can be seen, that for small imperfection values $\left(M_{i m p}=0.1,1 \mathrm{Nmm}\right)$ the solution follows the primary path up to the higher stress values, however it finally jumps onto the energetically stable path which can be obtained directly if higher imperfection values are adopted. For the sake of clarity in Fig. 6 the rotation field distribution is presented for the case of $M_{i m p}=0.1 \mathrm{Nmm}$. One can observe that up to stress value $P / A=32 \mathrm{MPa}$ the rotation field corresponds to the imposed concentrated imperfection. However, between stress values $P / A=32$ and $P / A=34.7 \mathrm{MPa}$ three different critical modes are detected. After the peak value $P / A=34.7 \mathrm{MPa}$ the solution returns to the path associated with the first mode induced by the imperfection.

Fig. 7 shows the stress-strain curves for both considered strips and discretizations, obtained for varying values of the Cosserat

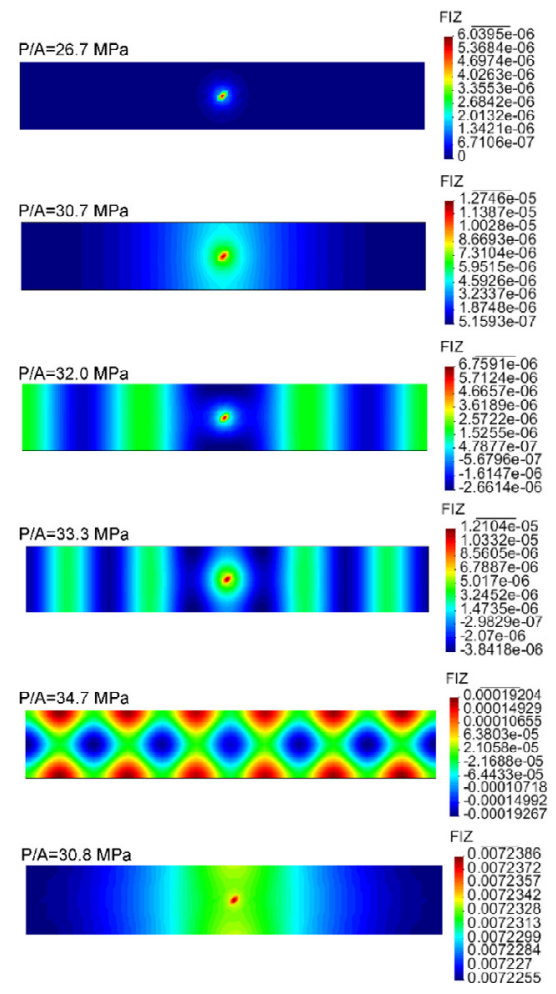

Fig. 6. Rotation field evolution for the small imperfection $M_{i m p}=0.1 \mathrm{Nmm}$, ideal steel strip $150 \times 25 \times 2 \mathrm{~mm}, N=0.01,24 \times 416 \mathrm{FI}$.

coupling number $(N=0.01,0.05,0.1,0.15)$. Similarly as for $N=$ 0.01 also for other values of $N$ a critical value of the stresses can be specified at which the path change is observed. The deforma- a)

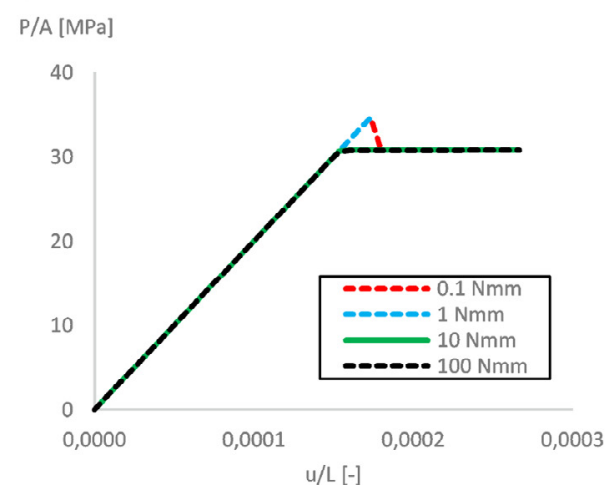

b)

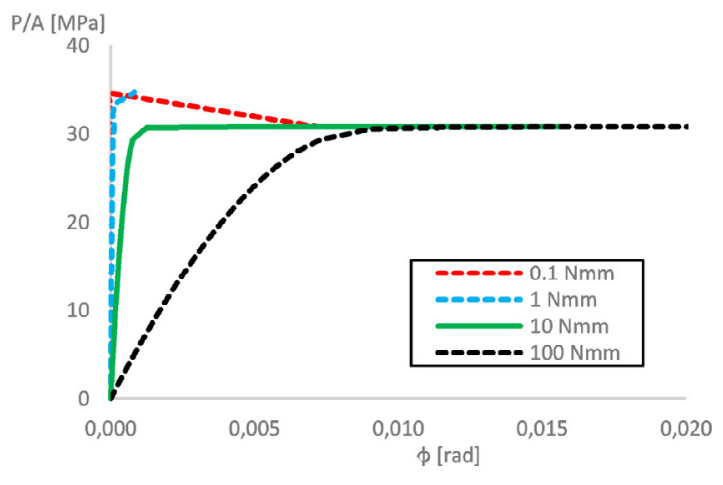

Fig. 5. Influence of the imperfection value, ideal steel strip $150 \times 25 \times 2 \mathrm{~mm}, N=0.01,24 \times 416 \mathrm{FI}$. 
a)

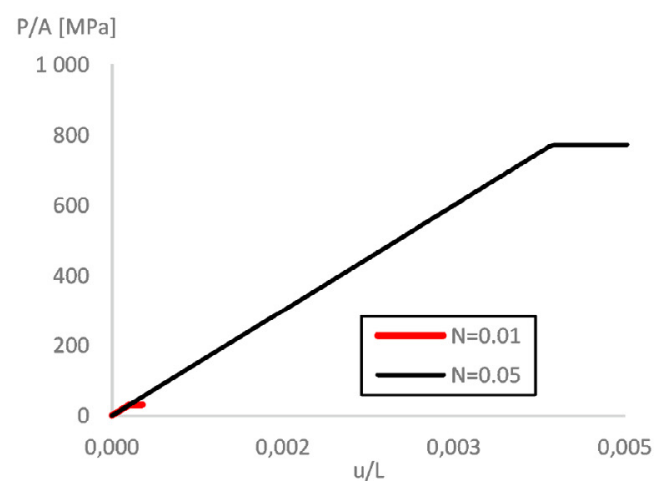

b)

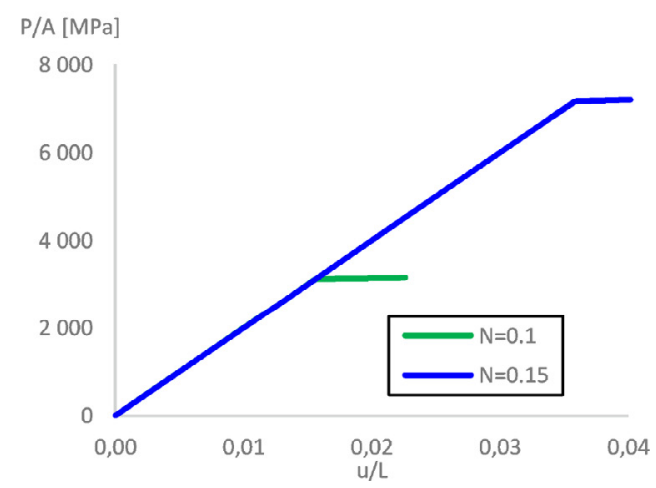

Fig. 7. Tensile stress-strain relation for ideal steel strips $150 \times 25 \times 2 \mathrm{~mm}$ and $100 \times 50 \times 0.5 \mathrm{~mm}$ for different values of $N$.

a)

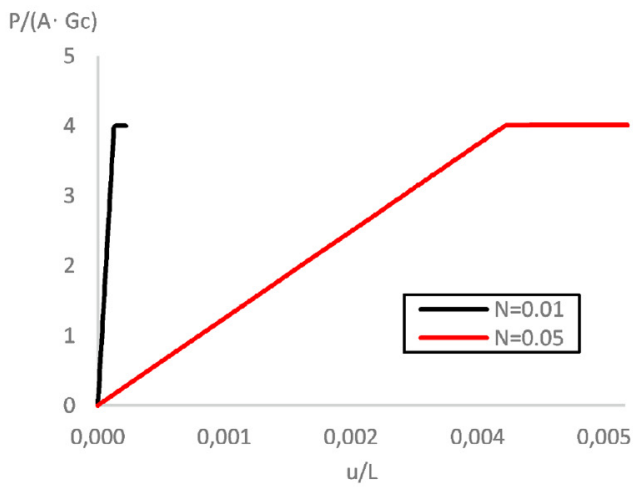

b)

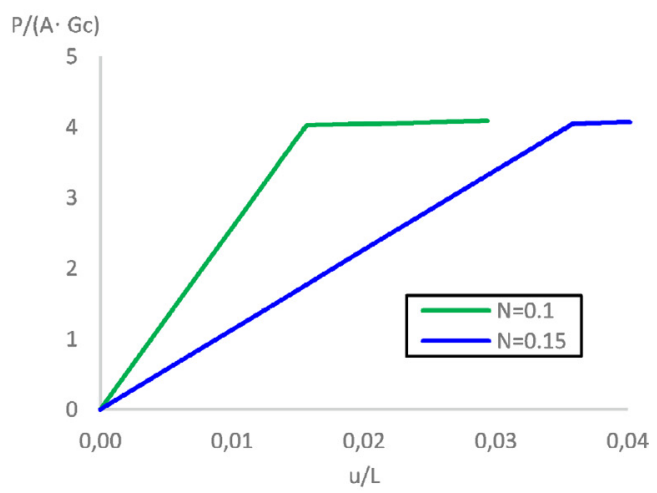

Fig. 8. Normalized tensile stress-strain relation for ideal steel strips $150 \times 25 \times 2 \mathrm{~mm}$ and $100 \times 50 \times 0.5 \mathrm{~mm}$ for different values of $\mathrm{N}$.

tion starts to be driven not only by the axial strain but also by the rotations. The value of critical stress increases with the growth of $N$. For $N=0.01 \sigma_{\text {crit }} \approx 31 \mathrm{MPa}$, for $N=0.05 \sigma_{\text {crit }} \approx 770 \mathrm{MPa}$, for $N=0.1 \sigma_{\text {crit }} \approx 3100 \mathrm{MPa}$, for $N=0.15 \sigma_{\text {crit }} \approx 7200 \mathrm{MPa}$.

The critical value of tensile stress obtained for $N=0.01$ $\left(\sigma_{\text {crit }} \approx 31 \mathrm{MPa}\right.$ ) is lower than distinctive yield point of steel and therefore it can influence the plastic deformation described with the usage of an appropriate constitutive law. The level of two latter critical stresses, however, is completely unphysical, since it exceeds the value of destructive stress characteristic for typical steel. The same remark concerns the strain values associated with critical tensile stresses. Therefore larger values of $N$ are not analyzed. The obtained solutions are strictly theoretical and it must be emphasized here, that this comment is valid for the majority of the results presented in the subsequent part of the paper and will not be underlined and discussed further.

For further considerations let us introduce the following normalization of the tensile stress

$\sigma^{\star}=\frac{\sigma}{G_{c}}=\frac{P}{A G_{c}}$.

Accordingly, the normalized critical tensile stress is given by

$\sigma_{\text {crit }}^{\star}=\frac{\sigma_{\text {crit }}}{G_{c}}=\frac{\sigma_{\text {crit }}}{G_{12}} \frac{1-N^{2}}{N^{2}}=\frac{P_{\text {crit }}}{A G_{12}} \frac{1-N^{2}}{N^{2}}$.

Fig. 8 illustrates the normalized tensile stress-strain curves for both considered geometries and different values of $N$. One can state, that in all the considered cases the normalized critical tensile stress is approximately equal to $4, \sigma_{\text {crit }}^{\star} \approx 4$.

From Figs. 4, 7 and 8 it is clear, that for each value of $N$ the solution does not depend on the geometry and mesh density.
Table 1

Material properties of the fixed strip.

\begin{tabular}{llllll}
\hline Material & $E_{1}[\mathrm{GPa}]$ & $E_{2}[\mathrm{GPa}]$ & $G_{12}[\mathrm{GPa}]$ & $v_{12}$ & $E_{1} / G_{12}$ \\
\hline $\begin{array}{l}\text { Isotropic (steel) } \\
\text { Bidirectional }\end{array}$ & 200 & 200 & 77 & 0.3 & 2.6 \\
$\begin{array}{l}\text { reinforced composite } \\
\text { (Sabik, 2018) }\end{array}$ & 23.4 & 23.4 & 3.52 & 0.153 & 6.7 \\
$\begin{array}{l}\text { Unidirectional } \\
\text { reinforced composite } \\
\text { (Nakamura et al., 1984) }\end{array}$ & 137.9 & 6.895 & 4.137 & 0.25 & 33.3 \\
\hline
\end{tabular}

Summarizing, following conclusions can be drawn:

- in Cosserat continuum a critical stress value can be obtained, at which in the axially loaded structure a rotation field is activated,

- the critical stress depends on the Cosserat coupling number,

- the critical stress is geometry independent.

\subsection{Example 2}

As the second example a fixed strip made of different materials is analyzed (Fig. 9). The data of materials which the strip is made of is collected in Table 1.

The material angle $\alpha$ (Fig. 9) is set to $\alpha=0$ if fiber reinforced composites are considered. Thus no transformation of the material law is required.

The last column of the Table 1 includes the ratio $E_{1} / G_{12}$, which can be treated as a measure of the material's shear flexibility. It is worth to emphasize that it is over 10 times larger for the chosen unidirectional composite than for steel. 


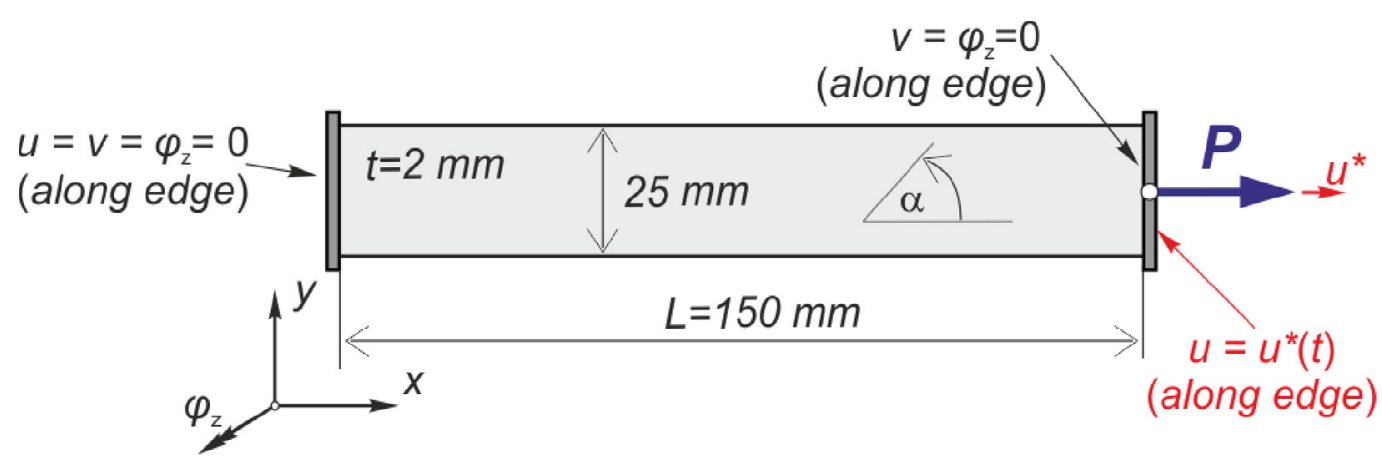

Fig. 9. Fixed strip - geometry and boundary conditions.

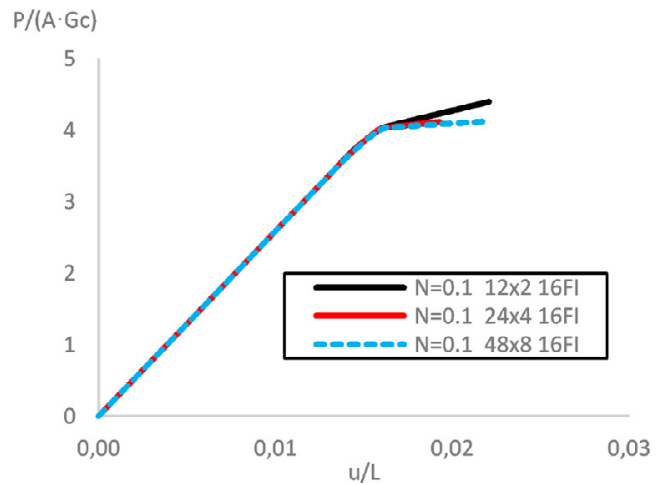

Fig. 10. Normalized tensile stress-strain relation for fixed steel strip, $N=0.1$, convergence study, 3 discretizations.

Fig. 10 depicts the convergence study performed for the steel strip for $N=0.1$. It shows that the mesh density influences only the post-critical behavior. This is typical also for other materials and other values of $N$, however, for large Cosserat coupling numbers the mesh density can have slight impact on the critical range. Nevertheless, this influence is not significant and therefore in all the considered cases in this example a fixed finite element division $24 \times 416$ FI is adopted.

Fig. 11 illustrates the normalized tensile stress-strain relation for the considered steel fixed strip obtained for different values of the Cosserat coupling number. Values larger than $N=0.5$ are not analyzed, since yet for these values the relative elongation $u / L$ of the sample is larger than 0.5 .

For the comparison purposes let us list the obtained nonnormalized critical tensile stresses corresponding to the values of
$N$ considered in the preceding example: for $N=0.05 \sigma_{\text {crit }} \approx 770$ MPa, for $N=0.1 \sigma_{\text {crit }} \approx 3100 \mathrm{MPa}$. These values match the results obtained for the ideal strip in the preceding problem. This allows to make a conclusion, that the critical tensile stress value does not depend on the boundary conditions and is only material dependent variable.

Similar results for the strip made of bidirectional and unidirectional reinforced composite are illustrated in Figs. 12 and 13, respectively. In bidirectional reinforced composite the instability takes place below the $u / L=0.5$ even for $N=0.7$ (Fig. 12). What is more the most shear flexible material loses the rotational stability below the elongation $u / L=0.15$ yet for $N=0.9$ (Fig. 13). From Figs. 11, 12, and 13, it follows, that regardless the adopted material, for small values of the Cosserat coupling number the normalized critical tensile stress is equal to 4 .

Fig. 14 presents the dependency of the normalized critical tensile stresses on the Cosserat coupling number for each considered material. The curves are confronted with the constant function $\sigma_{\text {crit }}^{\star}=4$. It can be seen, that for small values of $N$ all curves converge to $\sigma_{\text {crit }}^{\star}=4$ :

$\lim _{N \rightarrow 0} \sigma_{c r i t}^{\star}=4$.

In the case of steel the value of $\sigma_{\text {crit }}^{\star}$ increases with the growth of $N$, whereas it decreases in the case of composites.

Fig. 15 shows the evolution of the rotation field in the sample made of the unidirectional reinforced composite obtained for $N=0.4$. Let us recall, that in this example no imperfection is introduced. Here the boundary conditions disturb the homogeneity of the stress distribution in the support zones. This local inhomogeneity enforces the activation of the rotation field in the entire strip if the tensile stress approaches the critical value. For different values of $N$ and other materials the rotational field and defor- a)

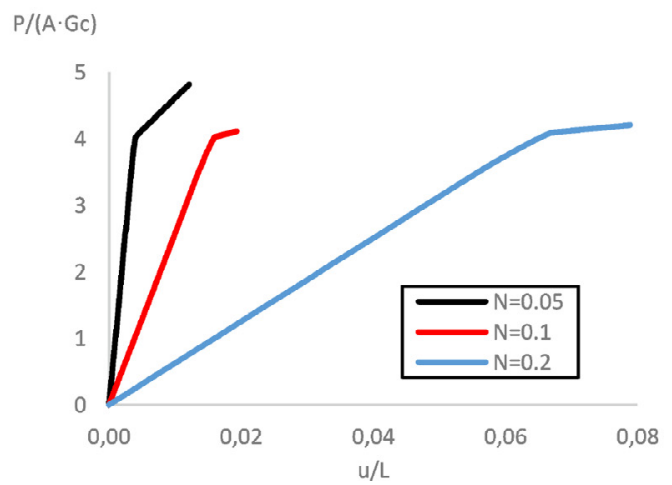

b)

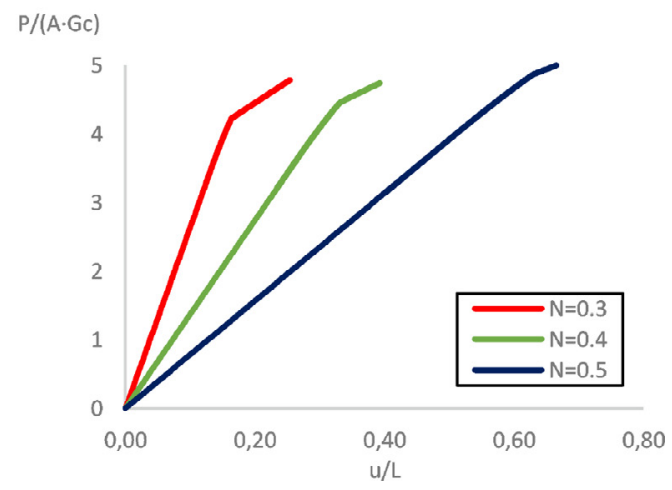

Fig. 11. Normalized tensile stress-strain relations for fixed steel strip $\left(E_{1} / G_{12}=2.6\right)$ for different values $N$, mesh $24 \times 416 \mathrm{FI}$. 
a)

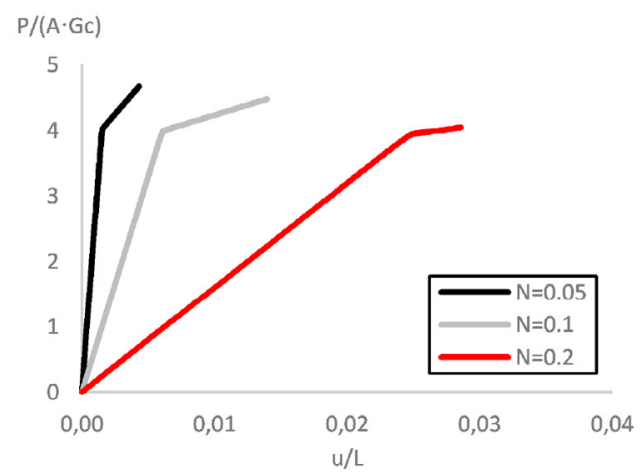

b)

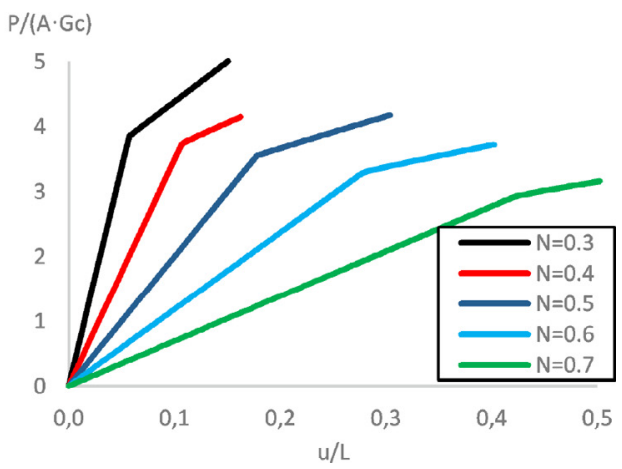

Fig. 12. Normalized tensile stress-strain relation for fixed strip (bidirectional composite $-E_{1} / G_{12}=6.7$ ) for different values $N$, mesh $24 \times 416 \mathrm{FI}$.

a)

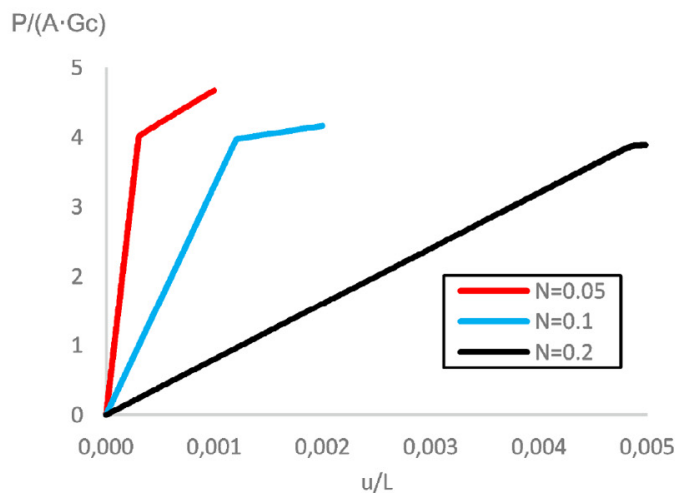

b)

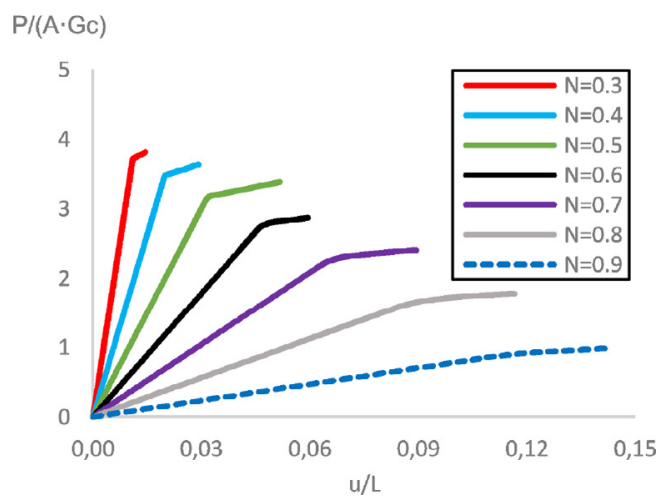

Fig. 13. Normalized tensile stress-strain relation for fixed strip (unidirectional composite $-E_{1} / G_{12}=33.3$ ) for different values $N$, mesh $24 \times 416 \mathrm{FI}$.

a)

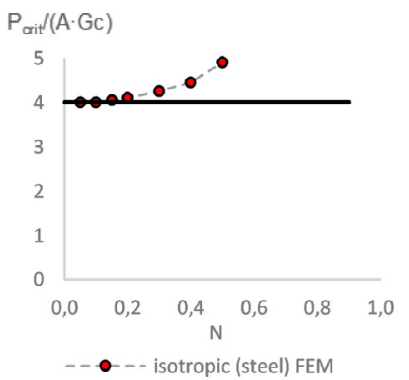

b)

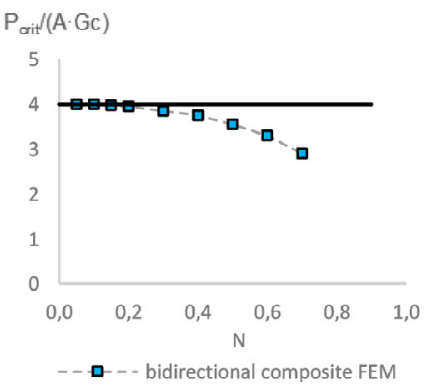

c)

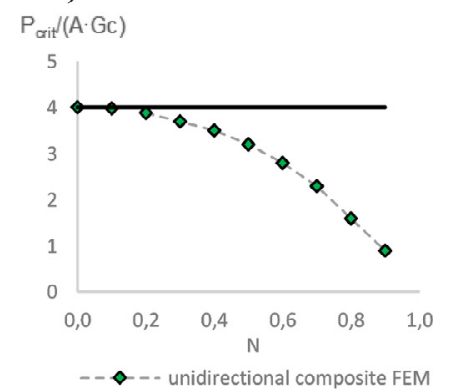

Fig. 14. Normalized critical tensile stress vs Cosserat coupling number.

mation are qualitatively the same, therefore only one case is presented.

As the summary of this example one can state:

- the rotation field can be induced by local shear/rotation zones present in the structure,

- the value of critical tensile stresses is material dependent variable,

- the value of critical tensile stresses depends nonlinearly on the Cosserat coupling number,

- for small Cosserat coupling numbers the normalized critical tensile stress tends to $4: \lim _{N \rightarrow 0} \sigma_{c r i t}^{\star}=4$,

- the larger the shear flexibility $\left(E_{1} / G_{12}\right)$ of the material the lower relative elongation associated with the rotational instability.

\subsection{Example 3}

As the last and summarizing problem a sample with a hole is considered, which is made of the unidirectional composite studied in the previous example (Table 1). Now, only one value of the Cosserat coupling number is chosen that is $N=0.2$. Due to the symmetry of the problem, only one quarter is analyzed (Fig. 16). The material angle $\alpha=0$.

Fig. 17 shows the normalized stress-strain curve obtained with the use of two mesh densities denoted by parameters $n, m$ (Fig. 16). Both meshes give the same solution, thus further convergence analysis is needless. The normalized tensile stress is understood as the ratio force per area of the mostly weakened crosssection of the sample A (Fig. 16) referenced to the Cosserat shear 

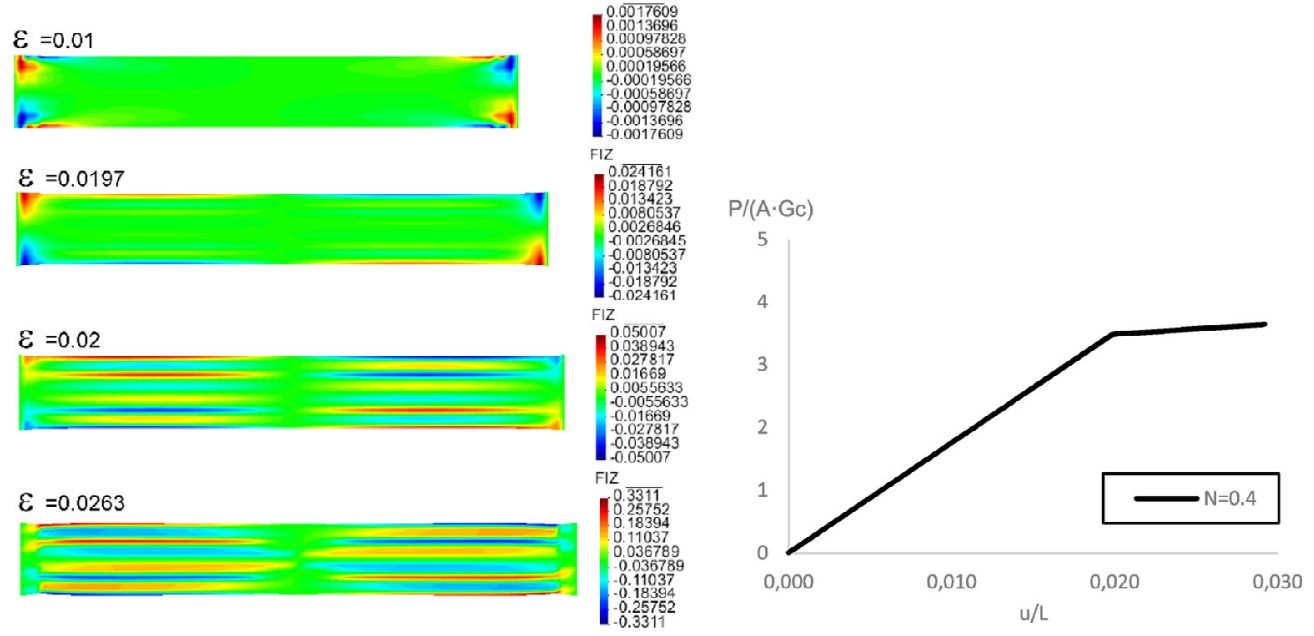

Fig. 15. Rotation field evolution (FIZ) and stress-strain curve of fixed strip, unidirectional reinforced composite, $N=0.4$.

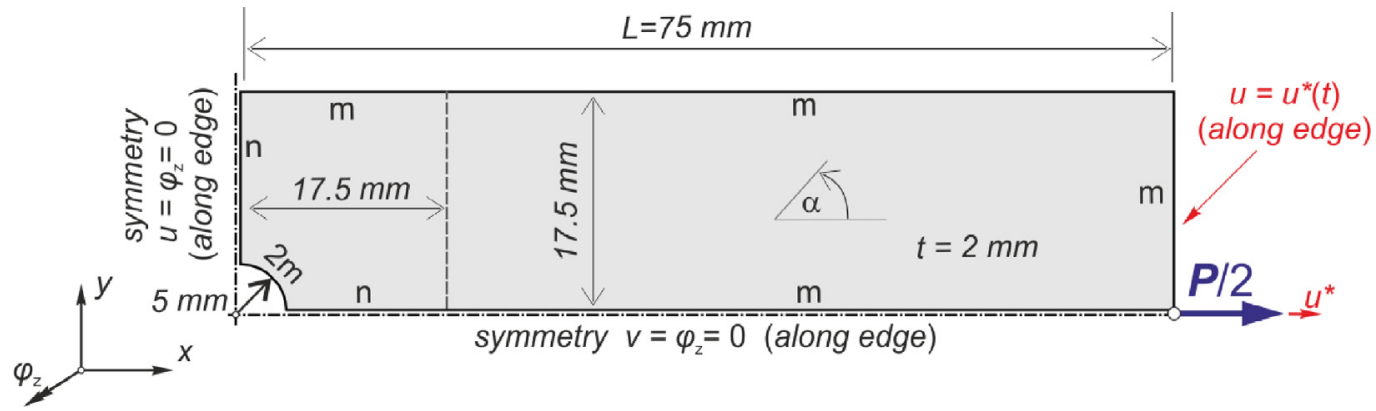

Fig. 16. Plate with the hole - geometry and boundary conditions.

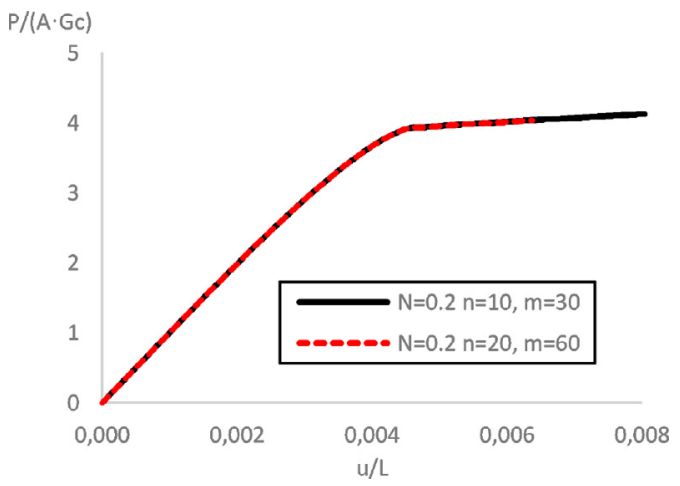

Fig. 17. Normalized tensile stress-strain relation for sample with the hole (unidirectional composite $\left.-E_{1} / G_{12}=33.3\right), N=0.2$, two discretizations.

modulus. Again, the relative elongation $u / L$ is chosen as the strain measure.

As in the previous studies a characteristic curve flexion can be observed at a certain normalized stress value. Furthermore similarly as previously for $N=0.2$ this value is equal to $\sigma_{\text {crit }} \approx 4$ (Fig. 14c).

A closer look at Fig. 17 indicates that the relative elongation corresponding to critical stresses is approximately $u / L \approx 0.0046$, which is in good agreement with the strain obtained in the preceding example for unidirectional composite and $N=0.2$ (see Fig. 13a).

Since in the considered problem a typical stress concentration is expected in the hole zone, the progress of the critical tensile stress field can be interesting. It is depicted in Fig. 18. The smoothness of the equilibrium path (Fig. 17) in the flexion vicinity is at-
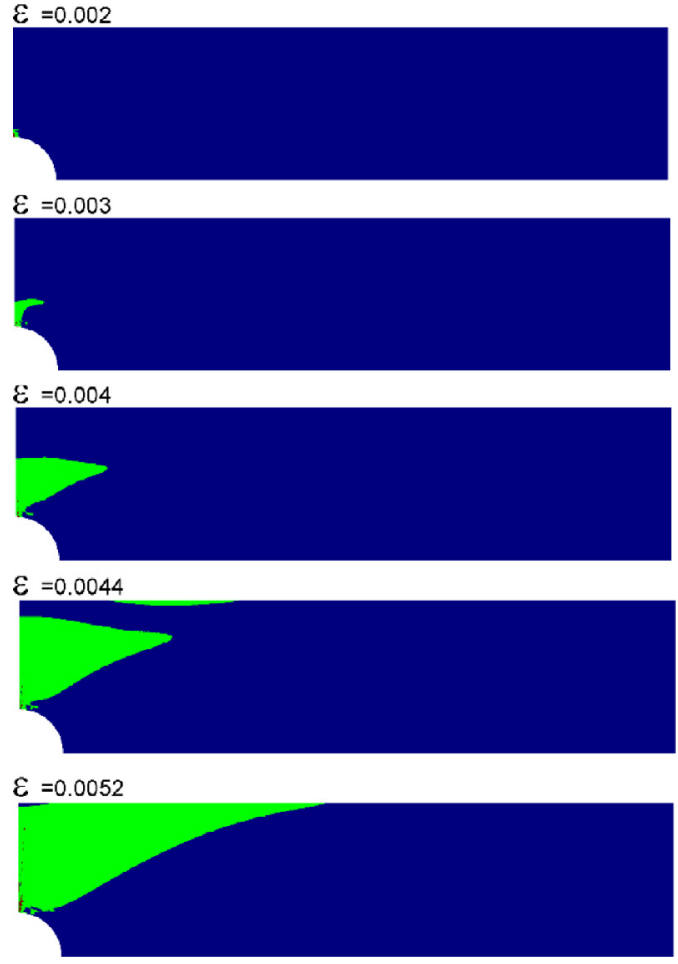

Fig. 18. Evolution of critical tensile stress zone (green) in the sample with the hole, $N=0.2$. (For interpretation of the references to color in this figure legend, the reader is referred to the web version of this article.) 
tributed to the gradual increase of the critical tensile stress zone in the hole-weakened region.

The example confirms the preceding statement, that critical tensile stress value at which the rotation field is activated is only material dependent value.

\section{Conclusions}

In the paper a new type of elastic bifurcation was discussed that is the rotational bifurcation which may occur under tensile loading of thin elastic structures modelled through the Cosserat approach. The origin of the bifurcation lies entirely in the appearance of the rotational degrees of freedom. Here in order to minimize the energy the structure under tension "escapes" into rotational mode when the load becomes greater than a certain critical value. After bifurcation we see softening related to the transmission of energy of deformation into rotational mode.

The numerical study reported in the paper confirms the theoretical considerations. It proves that in axially loaded Cosserat (micropolar) continuum at certain value of the tensile force the rotation field can be induced. The direct reason of this induction can be a local perturbation like small concentrated moment or stress concentration present in boundary zones. However, if the critical tensile force is achieved, the rotation field distributes from these local regions onto the entire structure. This feature makes the observed phenomenon similar to the classical buckling problem in which the bending deformation is initiated at critical axial compressive force. Therefore we named it the rotational instability. In particular, here a bifurcation occurs at the inclined forcedisplacement curve whereas for simple elastic materials the bifurcation of a bar under tensile force occurs only on the declined part of the inclined force-displacement curve (Zubov and Rudev, 1996). This differs micropolar materials for the Cauchy ones.

The examples studied in the paper allows one to make conclusions, that the critical tensile stress:

- is geometry independent,

- does not depend on the boundary conditions,

- is a material variable governed by the Cosserat coupling number,

- increases with the growth of the Cosserat coupling number,

- depends on the shear flexibility of the material - the larger the $E_{1} / G_{12}$ ratio the smaller the tensile strain is associated with the critical stress,

- the normalized value of the critical tensile stress tends to 4 if the Cosserat coupling number tends to 0 , i.e. $\lim _{N \rightarrow 0} \sigma_{\text {crit }}^{\star}=4$, where $\sigma_{\text {crit }}^{\star}=\sigma_{\text {crit }} / G_{c}$.

The last conclusion is surprising for the Authors and up till now the reason for this condition has not been found. The problem is planned to be analyzed in the future work. Another aspect which is worth consideration in the future is the postcritical behavior. In this paper it was indicated, that the mesh density does not influence the critical force value, however, it can have an impact on the postcritical response, which was not studied in details here.

\section{Declaration of Competing Interest}

The authors declare that they have no known competing financial interests or personal relationships that could have appeared to influence the work reported in this paper.

\section{Acknowledgmnts}

Francesco dell'Isola and Victor A. Eremeyev acknowledges the support of the Government of the Russian Federation (contract No. 14.Y26.31.0031).

\section{References}

Abdoul-Anziz, H., Seppecher, P., 2018. Strain gradient and generalized continua obtained by homogenizing frame lattices. Math. Mech. Compl. Syst. 6, 213-250.

Abdoul-Anziz, H., Seppecher, P., Bellis, C., 2019. Homogenization of frame lattices leading to second gradient models coupling classical strain and strain-gradient terms. Math. Mech. Solid. 24, 3976-3999.

Antman, S.S., 2005. Nonlinear Problems of Elasticity. volume 107 of seriesApplied Mathematical Sciences, 2nd ed. Springer Science+Business Media, New York.

Barchiesi, E., Spagnuolo, M., Placidi, L., 2019. Mechanical metamaterials: a state of the art. Math. Mech. Solid. 24, 212-234.

Bertolesi, E., Milani, G., Casolo, S., 2018. Homogenization towards a mechanistic rigid body and spring model (HRBSM) for the non-linear dynamic analysis of 3D masonry structures. Meccanica 53, 1819-1855.

Besdo, D., 2010. Towards a Cosserat-theory describing motion of an originally rectangular structure of blocks. Arch. Appl. Mech. 80, 25-45.

Bigoni, D., Bordignon, N., Piccolroaz, A., Stupkiewicz, S., 2018. Bifurcation of elastic solids with sliding interfaces. Proceed. Roy. Soc. A 474, 20170681.

Bigoni, D., Drugan, W.J., 2007. Analytical derivation of cosserat moduli via homogenization of heterogeneous elastic materials. Trans. ASME. J. Appl. Mech. 74 741-753.

Biswas, R., Poh, L.H., 2017. A micromorphic computational homogenization framework for heterogeneous materials. J. Mech. Phys. Solid. 102, 187-208.

Burzyński, S., Chróścielewski, J., Daszkiewicz, K., Witkowski, W., 2016. Geometrically nonlinear FEM analysis of FGM shells based on neutral physical surface approach in 6-parameter shell theory. Composit. Part B 107, 203-213.

Burzyński, S., Chróścielewski, J., Daszkiewicz, K., Witkowski, W., 2018. Elastoplastic nonlinear FEM analysis of FGM shells of cosserat type. Composit. Part B 154 478-491.

Casolo, S., 2004. Modelling in-plane micro-structure of masonry walls by rigid elements. Int. J. Solid. Struct. 41, 3625-3641.

Casolo, S., 2006. Macroscopic modelling of structured materials: relationship between orthotropic cosserat continuum and rigid elements. Int. J. Solid. Struct. 43, 475-496.

Casolo, S., Pena, F., 2007. Rigid element model for in-plane dynamics of masonry walls considering hysteretic behavior and damage. Earthq. Eng. Struct. Dyna. 36, 1029-1048.

Cazzani, A., Malagù, M., Turco, E., 2016. Isogeometric analysis of plane-curved beams. Math. Mech. Solid. 21, 562-577.

Cazzani, A., Malagù, M., Turco, E., Stochino, F., 2016. Constitutive models for strongly curved beams in the frame of isogeometric analysis. Math. Mech. Solid. 21, $182-209$.

Chróścielewski, J., Makowski, J., Pietraszkiewicz, W., 2004. Statyka i dynamika powłok wielopłatowych. nieliniowa teoria i metoda elementów skończonych (in polish). Wydawnictwo IPPT PAN, Warszawa.

Chróścielewski, J., Makowski, J., Stumpf, H., 1992. Genuinely resultant shell finite elements accounting for geometric and material non-linearity. Int J Numer Methods Eng 35, 63-94.

Chróścielewski, J., Makowski, J., Stumpf, H., 1997. Finite element analysis of smooth, folded and multi-shell structures. Comput. Method. Appl. Mech. Eng. 141, 1-46.

Chróścielewski, J., Sabik, A., Sobczyk, B., Witkowski, W., 2016. Nonlinear FEM 2D failure onset prediction of composite shells based on 6-parameter shell theory. Thin-walled Struct. 105, 207-219.

Chróścielewski, J., Sabik, A., Sobczyk, B., Witkowski, W., 2019. 2-D Constitutive equations for orthotropic cosserat type laminated shells in finite element analysis. Composit. Part B 165, 335-353.

Chróścielewski, J., Witkowski, W., 2006. Four-node semi-EAS element in six-field nonlinear theory of shells. Int. J. Numer. Method. Eng. 68, 1137-1179.

De Angelo, M., Barchiesi, E., Giorgio, I., Abali, B.E., 2019. Numerical identification of constitutive parameters in reduced-order bi-dimensional models for pantographic structures: application to out-of-plane buckling. Arch. Appl. Mech. 89, 1333-1358.

dell'Isola, F., Giorgio, I., Pawlikowski, M., Rizzi, N., 2016. Large deformations of planar extensible beams and pantographic lattices: heuristic homogenisation, experimental and numerical examples of equilibrium. Proceed. Roy. Soc. Lond. 472, 20150790.

dell'Isola, F., Seppecher, P., Alibert, J.J., Lekszycki, T., Grygoruk, R., Pawlikowski, M., Steigmann, D., Giorgio, I., Andreaus, U., Turco, E., Gołaszewski, M., Rizzi, N., Boutin, C., Eremeyev, V.A., Misra, A., Placidi, L., Barchiesi, E., Greco, L., Cuomo, M., Cazzani, A., Corte, A.D., Battista, A., Scerrato, D., Eremeeva, I.Z. Rahali, Y., Ganghoffer, J.F., Müller, W., Ganzosch, G., Spagnuolo, M., Pfaff, A., Barcz, K., Hoschke, K., Neggers, J., Hild, F., 2019. Pantographic metamaterials: an example of mathematically driven design and of its technological challenges. Continuum. Mech. Thermodyn. 31, 851-884.

dell'Isola, F., Seppecher, P., Spagnuolo, M., Barchiesi, E., Hild, F., Lekszycki, T., Giorgio, I., Placidi, L., Andreaus, U., Cuomo, M., Eugster, S.R., Pfaff, A., Hoschke, K. Langkemper, R., Turco, E., Sarikaya, R., Misra, A., De Angelo, M., D’Annibale, F., Bouterf, A., Pinelli, X., Misra, A., Desmorat, B., Pawlikowski, M., Dupuy, C., Scerrato, D., Peyre, P., Laudato, M., Manzari, L., Göransson, P., Hesch, C., Hesch, S., Franciosi, P., Dirrenberger, J., Maurin, F., Vangelatos, Z., Grigoropoulos, C., Melissinaki, V., Farsari, M., Muller, W., Abali, B.E., Liebold, C., Ganzosch, G., Harrison, P., Drobnicki, R., Igumnov, L., Alzahrani, F., Hayat, T., 2019. Advances in pantographic structures: design, manufacturing, models, experiments and image analyses. Continuum Mech. Thermodyn. 31, 1231-1282. 
El Nady, K., Dos Reis, F., Ganghoffer, J.F., 2017. Computation of the homogenized nonlinear elastic response of 2D and 3D auxetic structures based on micropolar continuum models. Compos. Struct. 170, 271-290.

Eremeev, V.V., Zubov, L.M., 2017. Buckling of a two-layered circular plate with a prestressed layer. Math. Mech. Solid. 22, 773-781.

Eremeyev, V.A., 2019. Two-and three-dimensional elastic networks with rigid junctions: modeling within the theory of micropolar shells and solids. Acta Mech. 230, 3875-3887.

Eremeyev, V.A., Altenbach, H., 2017. Basics of Mechanics of Micropolar Shells. In: Altenbach, H., Eremeyev, V.A. (Eds.), Shell-like Structures: Advanced Theories and Applications. Springer, Cham, pp. 63-111.

Eremeyev, V.A., Freidin, A.B., Pavlyuchenko, V.N., Ivanchev, S.S., 2007. Instability of hollow polymeric microspheres upon swelling. Dokl. Phys. 52, 37-40.

Eremeyev, V.A., Lebedev, L.P., Altenbach, H., 2013. Foundations of micropolar mechanics. Springer-Briefs in Applied Sciences and Technologies. Springer, Heidelberg et al..

Eremeyev, V.A., Pietraszkiewicz, W., 2006. Local symmetry group in the general theory of elastic shells. J. Elast. 85, 125-152.

Eremeyev, V.A., Pietraszkiewicz, W., 2012. Material symmetry group of the non-linear polar-elastic continuum. Int J Solids Struct 49, 1993-2005.

Eremeyev, V.A., Pietraszkiewicz, W., 2016. Material symmetry group and constitutive equations of micropolar anisotropic elastic solids. Math. Mech. Solid. 21, $210-221$.

Eremeyev, V.A., Turco, E., 2020. Enriched buckling for beam-lattice metamaterials. Mech Res Commun 103, 103458.

Eremeyev, V.A., Zubov, L.M., 1994. On the stability of elastic bodies with couple stresses. Mech. Solids 29, 172-181.

Eringen, A.C., 1999. Microcontinuum Field Theory. I. Foundations and Solids. Springer, New York.

Eugster, S.R., Hesch, C., Betsch, P., Glocker, C., 2014. Director-based beam finite elements relying on the geometrically exact beam theory formulated in skew coordinates. Int. J. Numer. Method. Eng. 97, 111-129.

Fu, Y.B., Ogden, R.W., 1999. Nonlinear stability analysis of pre-stressed elastic bodies. Continuum. Mech. Thermodyn. 11, 141-172.

Giorgio, I., Harrison, P., dell'Isola, F., Alsayednoor, J., Turco, E., 2018. Wrinkling in engineering fabrics: a comparison between two different comprehensive modelling approaches. Proceed. Roy. Soc. A 474, 20180063.

Goda, I., Assidi, M., Belouettar, S., Ganghoffer, J., 2012. A micropolar anisotropic constitutive model of cancellous bone from discrete homogenization. J. Mech. Behav. Biomed. Mater. 16, 87-108.

Goda, I., Assidi, M., Ganghoffer, J.F., 2014. A 3D elastic micropolar model of vertebral trabecular bone from lattice homogenization of the bone microstructure. Biomech. Model. Mechanobiol. 13, 53-83.

Greco, L., Cuomo, M., 2013. B-Spline interpolation of Kirchhoff-Love space rods. Comput Methods Appl Mech Eng 256, 251-269.

Greco, L., Cuomo, M., 2014. An implicit G1 multi patch B-spline interpolation for Kirchhoff-Love space rod. Comput Methods Appl Mech Eng 269, 173-197.

Green, A.E., Adkins, J.E., 1960. Large Elastic Deformations and Non-Linear Continuum Mechanics. Clarendon Press, Oxford.

Gurtin, M.E., Murdoch, A.I., 1975. A continuum theory of elastic material surfaces. Arch. Ration. Mech. Analy. 57, 291-323.

Hütter, G., 2019. On the micro-macro relation for the microdeformation in the homogenization towards micromorphic and micropolar continua. J. Mech. Phys. Solid. 127, 62-79.

Lakes, R.S., 1986. Experimental microelasticity of two porous solids. Int J Solids Struct 22, 55-63.

Lakes, R.S., 2018. Stability of cosserat solids: size effects, ellipticity and waves. J. Mech. Mater. Struct. 13, 83-91.

Leonetti, L., Greco, F., Trovalusci, P., Luciano, R., Masiani, R., 2018. A multiscale damage analysis of periodic composites using a couple-stress/cauchy multidomain model: application to masonry structures. Composit. Part B 141, 50-59.

Libai, A., Simmonds, J.G., 1998. The Nonlinear Theory of Elastic Shells, 2nd ed. Cambridge University Press, Cambridge.

Lurie, A.I., 1990. Nonlinear Theory of Elasticity. North-Holland, Amsterdam.

Masiani, R., Trovalusci, P., 1996. Cosserat and Cauchy materials as continuum models of brick masonry. Meccanica 31, 421-432.
Misra, A., Poorsolhjouy, P., 2016. Granular micromechanics based micromorphic model predicts frequency band gaps. Continuum. Mech. Thermodyn. 28, 215.

Misra, A., Poorsolhjouy, P., 2017. Grain-and macro-scale kinematics for granular micromechanics based small deformation micromorphic continuum model. Mech. Res.. Commun. 81, 1-6.

Nakamura, S., Benedict, R., Lakes, R., 1984. Finite element method for orthotropic micropolar elasticity. Int J Eng Sci 22, 319-330.

Niiranen, J., Balobanov, V., Kiendl, J., Hosseini, S.B., 2019. Variational formulations, model comparisons and numerical methods for euler-Bernoulli micro-and nano-beam models. Math. Mech. Solid. 24, 312-335.

Nowacki, W., 1986. Theory of Asymmetric Elasticity. Pergamon-Press, Oxford et al.. Ogden, R.W., 1997. Non-Linear Elastic Deformations. Dover, Mineola.

Panovko, Y.G., Gubanova, I.I., 1972. Stability and Oscillations of Elastic Systems, Paradoxes, Fallacies and New Concepts, 2nd ed. NASA, Washington.

Park, H.C., Lakes, R.S., 1986. Cosserat micromechanics of human bone: strain redistribution by a hydration sensitive constituent. J. Biomech. 19, 385-397.

Placidi, L., Barchiesi, E., Turco, E., Rizzi, N.L., 2016. A review on 2D models for the description of pantographic fabrics. Zeitschrift für angewandte Mathematik und Physik 67, 121.

Rahali, Y., Giorgio, I., Ganghoffer, J.F., dell'Isola, F., 2015. Homogenization à la piola produces second gradient continuum models for linear pantographic lattices. Int. J. Eng. Sci. 97, 148-172.

Reccia, E., De Bellis, M.L., Trovalusci, P., Masiani, R., 2018. Sensitivity to material contrast in homogenization of random particle composites as micropolar continua. Composit. Part B 136, 39-45.

Rubin, M.B., 2000. Cosserat Theories: Shells, Rods and Points. Kluwer, Dordrecht.

Rueger, Z., Lakes, R.S., 2016. Experimental cosserat elasticity in open-cell polymer foam. Philos. Mag. 96, 93-111.

Rueger, Z., Lakes, R.S., 2019. Experimental study of elastic constants of a dense foam with weak cosserat coupling. J. Elast. 137, 101-115.

Sabik, A., 2018. Direct shear stress vs strain relation for fiber reinforced composites, Composit. Part B 139, 24-30.

Scerrato, D., Giorgio, I., Rizzi, N.L., 2016. Three-dimensional instabilities of pantographic sheets with parabolic lattices: numerical investigations. Zeitschrift für angewandte Mathematik und Physik 67, 53.

Sheydakov, D.N., Altenbach, H., 2016. Stability of inhomogeneous micropolar cylindrical tube subject to combined loads. Math. Mech. Solid. 21, 1082-1094.

Suiker, A.S.J., Metrikine, A.V., de Borst, R., 2001. Comparison of wave propagation characteristics of the cosserat continuum model and corresponding discrete lattice models. Int. J. Solid. Struct. 38, 1563-1583.

Timoshenko, S.P., Gere, J.M., 1989. Theory of elastic stability, 2nd ed. Dover, Mineola.

Trovalusci, P., Pau, A., 2014. Derivation of microstructured continua from lattice systems via principle of virtual works: the case of masonry-like materials as micropolar, second gradient and classical continua. Acta Mech. 225, 157-177.

Turco, E., Golaszewski, M., Cazzani, A., Rizzi, N.L., 2016. Large deformations induced in planar pantographic sheets by loads applied on fibers: experimental validation of a discrete lagrangian model. Mech. Res. Commun. 76, 51-56.

Turco, E., Misra, A., Pawlikowski, M., dell'Isola, F., Hild, F., 2018. Enhanced piola-Hencky discrete models for pantographic sheets with pivots without deformation energy: numerics and experiments. Int. J. Solid. Struct. 147, 94-109.

Vardoulakis, I., 2019. Cosserat Continuum Mechanics: With Applications to Granular Media. Springer, Cham.

Vol'mir, A.S., 1970. Stability of deformable systems. Department of the Air Force Foreign Technology Division, Wright-Patterson AFB Dayton, OH 45433 US.

Walsh, S.D.C., Tordesillas, A., 2004. A thermomechanical approach to the development of micropolar constitutive models of granular media. Acta Mech. 167, 145-169.

Zaccaria, D., Bigoni, D., Noselli, G., Misseroni, D., 2011. Structures buckling under tensile dead load. Proceed. Roy. Soc. A 467, 1686-1700.

Zubov, L.M., Lastenko, M.S., 2004. On the instability of equilibrium of a cylinder made of a hardening material subjected to tension. Mech. Solid. 39, 109-116.

Zubov, L.M., Rudev, A.N., 1996. The instability of a non-linearly elastic beam under tension. J. Appl. Math. Mech. (PMM) 60, 777-788.

Zubov, L.M., Sheidakov, D.N., 2005. The effect of torsion on the stability of an elastic cylinder under tension. J. Appl. Math. Mech. (PMM) 69, 49-56. 